\title{
Chronic Caffeine Administration Exacerbates Renovascular, but Not Genetic, Hypertension in Rats
}

\author{
Akihiro Ohnishi, Robert A. Branch, Kimi Jackson, Reta Hamilton, Italo Biaggioni, Gilbert Deray, and Edwin K. Jackson \\ Division of Clinical Pharmacology, Departments of Pharmacology and Internal Medicine, \\ Vanderbilt University School of Medicine, Nashville, Tennessee 37232
}

\begin{abstract}
The purpose of this study was to determine whether or not caffeine would exacerbate renovascular hypertension. Therefore, we examined the effects of chronic caffeine administration on arterial blood pressure in rats subjected to either unilateral renal artery clipping (2K-1C rats) or sham-operation. Animals in each group were randomly assigned to receive either $0.1 \%$ caffeine in their drinking water or normal drinking water, and systolic blood pressure was monitored for 6 wk. Caffeine markedly exacerbated the severity of hypertension in $2 \mathrm{~K}-1 \mathrm{C}$ rats and caused histological changes consistent with malignant hypertension. 6 wk after surgery, systolic blood pressure, plasma renin activity, and creatinine clearance in control $2 \mathrm{~K}-1 \mathrm{C}$ rats were $169 \pm 5 \mathrm{mmHg}$ (mean \pm SEM), $4.4 \pm 0.5 \mathrm{ng} \mathrm{AI} \cdot \mathrm{ml}^{-1} \cdot \mathrm{h}^{-1}$, and $2.9 \pm 0.2 \mathrm{ml} / \mathrm{min}$, respectively; as compared with $219 \pm 4 \mathrm{mmHg}, 31.8 \pm 7.8 \mathrm{ng}$ $\mathrm{AI} \cdot \mathrm{ml}^{-1} \cdot \mathrm{h}^{-1}$, and $1.4 \pm 0.3 \mathrm{ml} / \mathrm{min}$, respectively, in $2 \mathrm{~K}-1 \mathrm{C}$ rats receiving caffeine (all values were significantly different compared with control 2K-1C). Chronic caffeine administration did not alter systolic blood pressure, plasma renin activity, or creatinine clearance in sham-operated rats or spontaneously hypertensive rats. Chronic treatment with enalapril (a converting enzyme inhibitor) prevented the development of hypertension in control $2 \mathrm{~K}-1 \mathrm{C}$ rats and caffeine-treated $2 \mathrm{~K}-1 \mathrm{C}$ rats; however, withdrawal of enalapril precipitated a rapid rise in systolic blood pressure in caffeine-treated $2 \mathrm{~K}-1 \mathrm{C}$ rats, but not in control $2 \mathrm{~K}-1 \mathrm{C}$ rats. These experiments indicate that caffeine specifically exacerbates experimental renovascular hypertension and might worsen the hypertensive process in patients with renovascular hypertension.
\end{abstract}

\section{Introduction}

Recently, we discovered that exogenous adenosine markedly attenuates the release of renin induced by renal artery hypotension (1). Since adenosine is an endogenously occurring substance, both in plasma and in renal tissue, it is possible that endogenous adenosine moderates the renal renin response to renal ischemia. The release of renin in response to renal ischemia plays a significant role in the pathophysiology of renovascular hypertension. If endogenous adenosine does indeed restrain the renal renin response to renal ischemia, then blockade of adenosine

Portions of this work were presented at the Southern Section Meeting of the American Federation for Clinical Research, New Orleans, LA, 58 February, 1986.

Address reprint requests to Dr. Jackson.

Received for publication 3 April 1986.

J. Clin. Invest.

(C) The American Society for Clinical Investigation, Inc. $0021-9738 / 86 / 10 / 1045 / 06 \$ 1.00$

Volume 78, October 1986, 1045-1050 receptors might enhance the release of renin in renovascular hypertension and, thereby, exacerbate the hypertension. Caffeine is a well-known antagonist of adenosine receptors $(2,3)$ and is widely consumed in large doses in coffee, tea, and some carbonated beverages. Given the theoretical considerations discussed above and given the ubiquitous consumption of caffeine by the world community, we felt that the effect of caffeine on blood pressure in renovascular hypertension should be investigated. Our results indicate that caffeine greatly exacerbates experimental renovascular hypertension. Further, we found that this effect was specific for renovascular hypertension and does not occur in a model of genetic hypertension.

\section{Methods}

Preparation of two-kidney-one-clip $(2 K-1 C)^{1}$ renovascular hypertensive rats. Male Sprague-Dawley rats ( 9 wk old; $234 \pm 21 \mathrm{~g}$; mean $\pm \mathrm{SD}$ ) were obtained from Sasco, Inc. (Omaha, NB) and acclimated to our animal care facility for at least $1 \mathrm{wk}$. Animals were anesthetized with pentobarbital $(50 \mathrm{mg} / \mathrm{kg}$, i.p.), and a midline incision was made in the abdomen. The cecum and part of the small intestines were exteriorized to enable access to the left kidney. All organs were kept moist with normal saline. The left renal artery was isolated, and a silver clip $(0.25-\mathrm{mm}$ gap) was placed around the left renal artery. In some animals the clip was removed (shamoperated rats) and in others the clip remained on the renal artery (2K$1 \mathrm{C}$ rats). The intestines were restored to their normal position, the abdominal wall was sutured with 4-0 silk suture, and the skin was held together using 9-mm wound clips. All animals were housed four to a cage in a central animal care facility, which provided a constant temperature $\left(22^{\circ} \mathrm{C}\right)$ and humidity and a light/dark cycle of $12 \mathrm{~h}$ (lights on from 6:00 a.m. to 6:00 p.m.). Rats were maintained on a diet of Wayne Lab-Blox (Allied Mills, Inc., Memphis, TN) containing 170 meq $\mathrm{Na}^{+} /$ $\mathrm{kg}$ and $246 \mathrm{meq} \mathrm{K}+\mathrm{kg}$ and water ad lib.

Tail cuff measurement of systolic blood pressure. Systolic blood pressure (SBP) was determined with a photoelectric tail cuff instrument (model 20-NW cuff pump, model 59 pulse amplifier, and model 65-24 manual scanner, II TC, Inc., Woodland Hills, CA) as previously described (4). Due to the increased sensitivity of this technique compared with the plethysmographic detection method, it was possible to determine SBP without prior heating when the animals were maintained at an ambient temperature of $27^{\circ} \mathrm{C}$. Therefore, this technique avoided heat stressing the animals. In each rat, SBP was monitored during three separate sessions weekly for $6 \mathrm{wk}$, and during each session, SBP was measured three times. For each rat, the average of these nine weekly measurements was taken as the SBP for a given week.

Effect of caffeine on the depressor response to adenosine. The purpose of our study was to determine the effects of chronic caffeine administration, at doses providing sustained inhibition of adenosine receptors, on arterial blood pressure in renovascular hypertensive rats. Before this goal could be achieved, a dose-regimen for caffeine administration that afforded blockade of adenosine receptors had to be found. A previously

1. Abbreviations used in this paper: ANOVA, analysis of variance; $2 \mathrm{~K}$ 1C, two-kidney-one-clip; SBP, systolic blood pressure; SHR, spontaneously hypertensive rats; SNK, Student-Newman-Keuls. 
published study indicated that $0.1 \%$ caffeine in drinking water provided sufficient caffeine intake to cause sustained adenosine receptor inhibition (5). To verify that this was indeed true in our hands, we examined the influence of $0.1 \%$ caffeine in drinking water on vascular responses to adenosine in conscious, unrestrained rats.

Normotensive male Sprague-Dawley Rats (14-15 wk of age) were randomized to receive either $0.1 \%$ caffeine in drinking water $(n=6)$ or drinking water without caffeine $(n=6)$. After $1 \mathrm{wk}$, animals were anesthetized with pentobarbital, and the jugular vein and carotid artery were cannulated with polyethylene- 50 tubing. The cannulae were tunneled subcutaneously to the back of the neck and exteriorized. The animals were fitted with a protective jacket (Alice King Chatham Medical Arts, Los Angeles, CA), and the catheters were protected with a metal coil and were connected to a miniature channel swivel. Animals could move freely, eat, and drink once they regained consciousness. At least $24 \mathrm{~h}$ after surgery, depressor responses to adenosine were determined by infusing increasing doses of adenosine $(0.066,0.1,0.33$, and $0.66 \mathrm{mg} / \mathrm{kg}$ per min) into the jugular vein (15 min per dose) while monitoring arterial blood pressure via the carotid cannula. Blood pressure was monitored via a pressure transducer (Hewlett-Packard Co., Palo Alto, CA) interfaced with a recorder (model 7768A; Hewlett-Packard Co.)

As shown in Fig. 1, the dose-depressor response curve to adenosine was shifted significantly to the right in caffeine-treated animals compared with non-caffeine-treated animals. The shift in the dose response curve was parallel, which suggests competitive inhibition of adenosine receptors by the plasma level of caffeine achieved with $0.1 \%$ caffeine in drinking water. Importantly, this dose of caffeine did not cause any abnormal behavior, activity, or sleep pattern in this group or any of the other groups of rats studied.

Protocol A: caffeine in $2 \mathrm{~K}-1 \mathrm{C}$ and sham-operated rats. $272 \mathrm{~K}-1 \mathrm{C}$ rats were randomized to receive either $0.1 \%$ caffeine as drinking water $(2 \mathrm{~K}$ $1 \mathrm{C}$ caffeine I group; $n=8$ ) or drinking water without caffeine (2K-1C no caffeine group; $n=19$ ). Treatment with caffeine began immediately after surgery in the $2 \mathrm{~K}-1 \mathrm{C}$ caffeine I group. After $3 \mathrm{wk}$, the surviving animals $(n=16)$ in the no caffeine group were randomized to continue in the $2 \mathrm{~K}-1 \mathrm{C}$ no caffeine group $(n=8)$ or to receive $0.1 \%$ caffeine as drinking water ( $2 \mathrm{~K}-1 \mathrm{C}$ caffeine II group; $n=8$ ). In addition, 16 shamoperated rats were randomized to receive either $0.1 \%$ caffeine in drinking water (sham-caffeine group; $n=8$ ) or drinking water without caffeine (sham-control group; $n=8$ ). Treatment with caffeine began immediately after surgery in the sham-caffeine group. In all groups, SBP was monitored for $6 \mathrm{wk}$ as described above, and at the end of the study rats were housed individually in metabolic cages (Nalge Co., Rochester, NY) for $72 \mathrm{~h}$. During the last $24 \mathrm{~h}$, food intake, water intake, and urine output were determined. Urine samples were analyzed for sodium and creatinine levels. Finally, animals were rapidly decapitated, and the first $3 \mathrm{~s}$ of blood

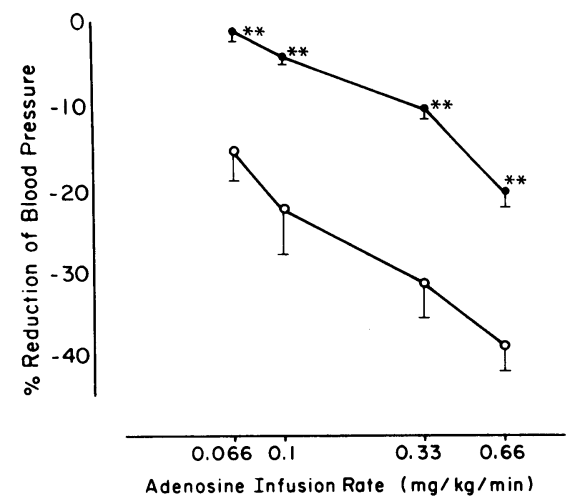

Figure 1. Effects of caffeine on depressor responses to intravenous infusions of adenosine. Caffeine significantly (two-way analysis of variance [ANOVA]) shifted the adenosine dose-response curve to the right. (- - $0.1 \%$ caffeine in drinking water, $n=6$. (-० -) No caffeine, $n=6 . * *, P<0.01$ (caffeine vs. no caffeine). were collected for determination of plasma renin activity (6). Additional blood was collected for measurement of plasma creatinine level, plasma sodium concentration, and, in the $2 \mathrm{~K}-1 \mathrm{C}$-caffeine I, $2 \mathrm{~K}-1 \mathrm{C}$ caffeine II, and sham-caffeine groups, plasma caffeine level.

Protocol B: caffeine in enalapril-treated $2 K-1 C$ rats. 16 rats were randomized to receive either $0.1 \%$ caffeine as drinking water $(n=8)$ or drinking water without caffeine $(n=8)$. After $1 \mathrm{wk}$ of pretreatment, a silver clip was placed on the left renal artery of all 16 rats as described above. Immediately after surgery, enalapril was added to the drinking water of all 16 rats to give a final concentration of $0.03 \%$ enalapril. The enalapril treatment was maintained for $3 \mathrm{wk}$ and then withdrawn, whereas treatment with caffeine was continued in the group initially randomized to caffeine. SBP was monitored for $6 \mathrm{wk}$ as described above. At the end of the study, food intake, water intake, urine output, sodium and creatinine levels in plasma and urine, and plasma renin activity were determined as described in protocol $\mathrm{A}$.

Protocol C: caffeine in spontaneously hypertensive rats (SHR). Fivewk-old SHR of the Okamoto-Aoki strain (Taconic Farms, Inc., Germantown, NY) were acclimated to our animal care facility for $1 \mathrm{wk}$ and then randomized to receive either $0.1 \%$ caffeine in drinking water or drinking water without caffeine at $6 \mathrm{wk}$ of age. SBP was monitored weekly, as described above, for $7 \mathrm{wk}$. At the end of the study, food intake, water intake, urine output, sodium and creatinine levels in plasma and urine, and plasma renin activity were determined as described in protocol $\mathrm{A}$.

Sample analysis. Blood samples for plasma renin activity were collected in prechilled tubes containing $50 \mu \mathrm{l}$ of $10 \%$ EDTA and placed immediately on ice. Samples were centrifuged at $4^{\circ} \mathrm{C}$, and the plasma was frozen $\left(-20^{\circ} \mathrm{C}\right)$ until assayed for plasma renin activity as previously described (7). Plasma and urine were analyzed for creatinine using a creatinine autoanalyzer (Beckman Instruments, Inc., Fullerton, CA) and for sodium using a flame photometer.

Plasma caffeine levels were determined using a variation of a previously described method (8). Briefly, $100 \mu \mathrm{l}$ of beta-hydroxyethyltheophylline $(10 \mathrm{mg} / \mathrm{ml}$; internal standard) was added to $100 \mu \mathrm{l}$ of plasma, and this solution was loaded onto a 1-ml reverse-phase (C-18) column (Bond Elut; Analytichem International, Inc., Harbor City, CA) that previously had been activated with $2 \mathrm{ml}$ of methanol and washed with 2 $\mathrm{ml}$ of distilled water. After loading the sample, the column was washed with $2 \mathrm{ml}$ of distilled water, and methylxanthines were eluted with 400 $\mu \mathrm{l}$ of acetone. Caffeine was analyzed with a high pressure liquid chromatographic system consisting of a pump (model M45; Waters Assoc., Milford, MA), an injector (Rheodyne, Inc., Cotati, CA), a 5- $\mu \mathrm{m}$ column (Biophase OD5; Bioanalytical Systems, Inc., West Lafayette, IN), and an ultraviolet detector (model 160; Beckman Instruments, Inc.) set at a wavelength of $280 \mathrm{~nm}$ and a sensitivity of 0.25 absorbance unit full scale. The mobile phase, consisting of $2 \%$ acetic acid and $6 \%$ acetonitrile, was delivered at a flow rate of $1.5 \mathrm{ml} / \mathrm{min}$ at $\sim 2,000 \mathrm{psi}$. After evaporation under nitrogen, the sample was reconstituted in $100 \mu l$ of mobile phase, and $10 \mu \mathrm{l}$ was injected into the chromatographic system. Caffeine levels were determined by comparing the peak height ratios of caffeine to internal standard against a standard curve in methylxanthine-free plasma.

Statistical analysis. The time-SBP relationships between caffeinetreated and non-caffeine-treated animals were compared by two-factor ANOVA using the Statistical Package for the Social Sciences on the Vanderbilt Digital Equipment Corporation 1099 computer. Comparisons between caffeine and non-caffeine-treated animals at specific time points were made using a two-tailed, unpaired Student's $t$ test. Multiple comparisons among all five groups were performed using a Student-NewmanKeuls (SNK) test. The criterion of significance was $P<0.05$. All valves in text and figures indicate mean \pm SEM.

\section{Results}

Protocol A: caffeine in $2 K-1 C$ and sham-operated rats. The effects of caffeine on SBP in $2 \mathrm{~K}-1 \mathrm{C}$ and sham-operated animals are summarized in Fig. 2. Before surgery, all four groups of animals had similar SBPs. After placing a silver clip on one renal artery, SBP rose over the course of 3-4 wk in the $2 \mathrm{~K}-1 \mathrm{C}$ no caffeine 


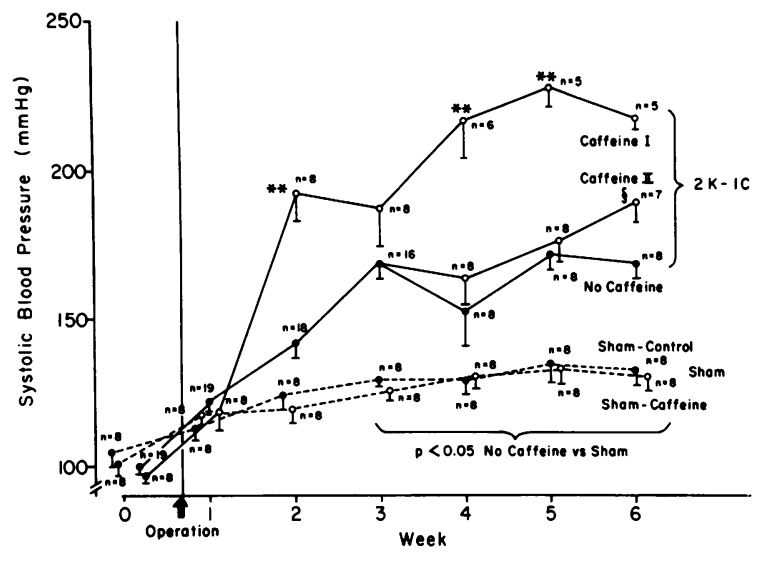

Figure 2. Effects of caffeine on systolic blood pressure in $2 \mathrm{~K}-1 \mathrm{C}$ and sham-operated rats. After obtaining baseline systolic blood pressure, animals were subjected to either renal artery clipping or sham-operation. In the $2 \mathrm{~K}-1 \mathrm{C}$ caffeine I group, $2 \mathrm{~K}-1 \mathrm{C}$ animals were treated with caffeine beginning immediately after surgery, whereas in the $2 \mathrm{~K}-1 \mathrm{C}$ caffeine II group, $2 \mathrm{~K}-1 \mathrm{C}$ animals did not receive caffeine until 3 wk after renal artery clipping. The $2 \mathrm{~K}-1 \mathrm{C}$ no caffeine group, consisting of $2 \mathrm{~K}-1 \mathrm{C}$ animals not treated with caffeine, served as a control. The sham-caffeine group consisted of sham-operated animals that received caffeine beginning just after surgery, whereas the sham-control group was made up of sham-operated animals that did not receive caffeine. Statistics in the figure refer to unpaired Student's $t$ test. The timepressure relationships for the $2 \mathrm{~K}-1 \mathrm{C}$ caffeine I group and the $2 \mathrm{~K}-1 \mathrm{C}$ caffeine II group were significantly different (two-way ANOVA) compared with the time-pressure relationship for the $2 \mathrm{~K}-1 \mathrm{C}$ no caffeine group. Caffeine did not influence systolic blood pressure in sham-operated rats. $\bullet$, No caffeine in drinking water; $0,0.1 \%$ caffeine in drinking water; **, $P<0.01$ (caffeine I vs. caffeine II or no caffeine); $\S, P<0.05$ (caffeine II vs. no caffeine).

group and in the $2 \mathrm{~K}-1 \mathrm{C}$ caffeine I group. However, SBP rose more rapidly and achieved a higher maximum in the $2 \mathrm{~K}-1 \mathrm{C}$ caffeine I group. The overall time-pressure relationships for the $2 \mathrm{~K}-1 \mathrm{C}$ caffeine I group and the $2 \mathrm{~K}-1 \mathrm{C}$ no caffeine group were significantly different by two-way ANOVA $(P<0.001)$. Also, the SBP in the $2 \mathrm{~K}-1 \mathrm{C}$ caffeine I group was significantly $(P<0.01)$ higher than the SBP in the $2 \mathrm{~K}-1 \mathrm{C}$ no caffeine group at $2,4,5$, and $6 \mathrm{wk}$ into the study ( $t$ tests). At $6 \mathrm{wk}$ into the study, the SBP in the $2 \mathrm{~K}-1 \mathrm{C}$ caffeine I group was $219 \pm 4 \mathrm{mmHg}$, whereas in the $2 \mathrm{~K}-1 \mathrm{C}$ no caffeine group the SBP was only $169 \pm 5 \mathrm{mmHg}$.

3 of 19 animals in the $2 \mathrm{~K}-1 \mathrm{C}$ no caffeine group died during the first 3 wk after surgery, leaving 16 animals in the $2 \mathrm{~K}-1 \mathrm{C}$ no caffeine group. $3 \mathrm{wk}$ after surgery, these 16 animals in the $2 \mathrm{~K}$ IC no caffeine group were randomized to either caffeine ( $n$ $=8)$ or no caffeine $(n=8)$. The SBP of the group randomized to caffeine, i.e., the $2 \mathrm{~K}-1 \mathrm{C}$ caffeine II group, continued to experience a rise in SBP; whereas, the SBP in the $2 \mathrm{~K}-1 \mathrm{C}$ no caffeine group seemed to plateau. The overall time-pressure relationships for the $2 \mathrm{~K}-1 \mathrm{C}$ caffeine II group and the $2 \mathrm{~K}-1 \mathrm{C}$ no caffeine group were significantly different by two-way ANOVA $(P<0.05)$, and by $6 \mathrm{wk}$ postsurgery; i.e., $3 \mathrm{wk}$ after beginning caffeine treatment, the SBP in the $2 \mathrm{~K}-1 \mathrm{C}$ caffeine II group was significantly $(P$ $<0.05 ; t$ test) higher than the SBP in the $2 \mathrm{~K}-1 \mathrm{C}$ no caffeine group ( $190 \pm 6$ vs. $169 \pm 5 \mathrm{mmHg}$, respectively).

The SBP in the sham-control and sham-caffeine groups rose only slightly after surgery. The time-pressure relationships for the sham-control group and sham-caffeine group were nearly identical. However, the time-pressure relationship for the $2 \mathrm{~K}$ $1 \mathrm{C}$ no caffeine group was significantly $(P<0.001)$ different compared with the time-pressure relationships for the shamcontrol or sham-caffeine groups when compared by two-way ANOVA.

Urine volume, water intake, food intake, plasma sodium concentration, and urinary sodium excretion did not differ significantly among the five groups at $6 \mathrm{wk}$ past surgery (Table I). Plasma renin activity was approximately seven times higher in the $2 \mathrm{~K}-1 \mathrm{C}$ caffeine I group $(P<0.05 ; \mathrm{SNK})$ and 1.6 times greater in the $2 \mathrm{~K}-1 \mathrm{C}$ caffeine II group $(P<0.05 ; \mathrm{SNK})$ compared with the $2 \mathrm{~K}-1 \mathrm{C}$ no caffeine group (Table I). The higher levels of renin probably account for the trend toward a higher fluid intake and urine volume in the $2 \mathrm{~K}-1 \mathrm{C}$ caffeine I group, since angiotensin II is a potent dipsogenic agent (9). Plasma renin activity was significantly lower in the sham-caffeine or sham-control groups compared with any of the three $2 \mathrm{~K}-1 \mathrm{C}$ groups $(P<0.05$; SNK). Creatinine clearance in the $2 \mathrm{~K}-1 \mathrm{C}$ caffeine I group was reduced by approximately one-half $(P<0.05$; SNK $)$ compared with any of the other four groups, whereas creatinine clearances were similar in all other groups. Plasma caffeine levels in caffeine I, II, and sham-caffeine groups were $10.5 \pm 3.4,15.6 \pm 1.8$, and $9.9 \pm 4.0 \mu \mathrm{g} / \mathrm{ml}$, respectively.

Table I. Metabolic and Biochemical Studies at the End of $6 \mathrm{Wk}$ in Protocol A

\begin{tabular}{|c|c|c|c|c|c|}
\hline & \multicolumn{3}{|l|}{$2 \mathrm{~K}-1 \mathrm{C}$ rats } & \multicolumn{2}{|c|}{ Sham-operated rats } \\
\hline & Caffeine I & Caffeine II & No caffeine & Sham-caffeine & Sham-control \\
\hline & $n=5$ & $n=7$ & $n=8$ & $n=8$ & $n=8$ \\
\hline${ }^{*}$ Urine volume $(\mathrm{ml} / \mathrm{d})$ & $27 \pm 4$ & $15 \pm 1$ & $18 \pm 1$ & $15 \pm 1$ & $18 \pm 1$ \\
\hline *Water intake (ml/d) & $42 \pm 7$ & $32 \pm 2$ & $21 \pm 1$ & $28 \pm 1$ & $34 \pm 1$ \\
\hline${ }^{*}$ Food intake $(g / d)$ & $19 \pm 3$ & $21 \pm 1$ & $21 \pm 1$ & $20 \pm 1$ & $22 \pm 2$ \\
\hline *Plasma sodium concentration (meq/liter) & $145 \pm 4$ & $145 \pm 3$ & $142 \pm 4$ & $138 \pm 2$ & $138 \pm 2$ \\
\hline${ }^{*}$ Urinary sodium excretion $(\mu e q / d)$ & $1,269 \pm 146$ & $1,931 \pm 278$ & $1,736 \pm 99$ & $1,717 \pm 116$ & $1,822 \pm 90$ \\
\hline Plasma renin activity $\left(n g A I \cdot m l^{-1} \cdot h^{-1}\right)$ & $\overline{31.8 \pm 7.8}$ & $\overline{7.0 \pm 1.1}$ & $\overline{4.4 \pm 0.5}$ & $\overline{1.9 \pm 0.4}$ & $1.8 \pm 0.4$ \\
\hline Creatinine clearance $(\mathrm{ml} / \mathrm{min})$ & $\overline{1.4 \pm 0.3}$ & $2.5 \pm 0.6$ & $2.9 \pm 0.2$ & $3.0 \pm 0.7$ & $3.0 \pm 0.6$ \\
\hline${ }^{*}$ Plasma caffeine levels $(\mu \mathrm{g} / \mathrm{ml})$ & $10.5 \pm 3.4$ & $15.6 \pm 1.8$ & 一 & $9.9 \pm 4.0$ & - \\
\hline
\end{tabular}

Values indicate mean \pm SEM. Bars interconnect all values that are not significantly different from one another $(P>0.05)$. ${ }^{*}$ Indicates no significant differences among the five groups (Student-Newman-Keuls test). 
The right kidneys were removed from five animals each in the $2 \mathrm{~K}-1 \mathrm{C}$ caffeine I group, $2 \mathrm{~K}-1 \mathrm{C}$ caffeine II group, and $2 \mathrm{~K}$ $1 \mathrm{C}$ no caffeine group and were submitted for histological examination. The pathologist did not know from which group a particular kidney had been obtained. Three of five kidneys from the 2K-1C caffeine I group exhibited fibrinoid necrosis of the afferent arterial (onion skin lesion) and concentric internal fibroplasia in some arteries. Such lesions were not observed in any of the kidneys taken from the $2 \mathrm{~K}-1 \mathrm{C}$ caffeine II group or the $2 \mathrm{~K}-1 \mathrm{C}$ no caffeine group.

During the last 3 wk of the study, three of eight rats died in the caffeine I group, and one of eight rats died in the caffeine II group. However, during this same time, no rats died in the no caffeine, sham-control, or sham-caffeine groups.

Protocol B: caffeine in enalapril-treated $2 \mathrm{~K}-1 \mathrm{C}$ rats. As shown in Fig. 3, 2K-1C rats receiving enalapril ( $0.03 \%$ in drinking water) did not develop hypertension regardless of whether or not caffeine was administered concomitantly with the enalapril. Upon withdrawal of enalapril, SBP began to rise in both the non-caffeinetreated and the caffeine-treated animals; however, SBP rose much more rapidly in the caffeine-treated animals compared with the non-caffeine-treated animals $(P<0.001$, two-way ANOVA), and the SBP was elevated to a much greater extent $(P<0.01 ; t$ test) at 1, 2, and 3 wk after withdrawal of enalapril (i.e., 4, 5, and 6 wk after surgery) in the caffeine-treated vs. the non-caffeine-treated animals. As shown in Table II, at the end of the study, urine volume, water intake, food intake, plasma sodium concentration, urinary sodium excretion, and creatinine clearance were not significantly different between the two groups. However, plasma renin activity was approximately seven times higher in $2 \mathrm{~K}-1 \mathrm{C}$ rats receiving caffeine compared with control 2K-1C rats (Table II).

Protocol C: caffeine in SHR. In SHR, SBP rose progressively with age in both the caffeine-treated and non-caffeine-treated animals (Fig. 4). Caffeine treatment did not enhance the devel-

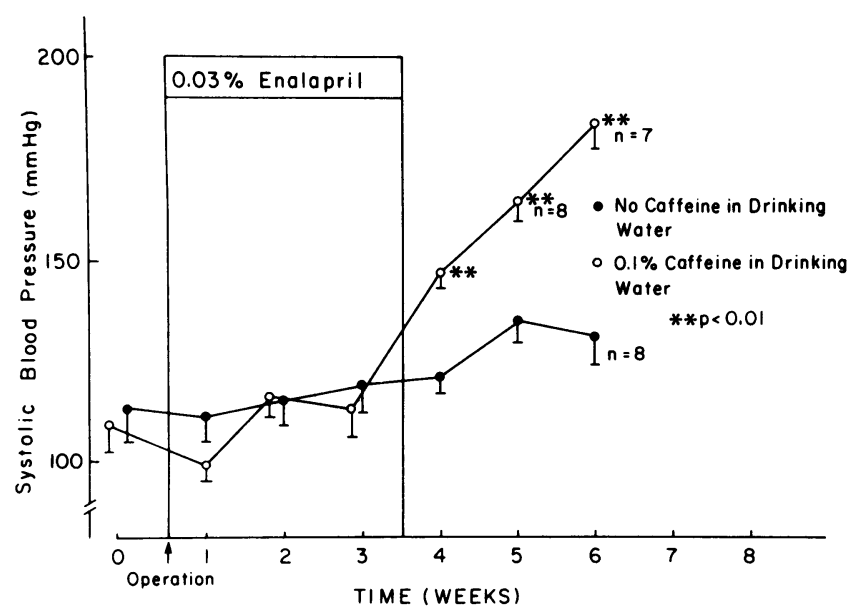

Figure 3. Effects of caffeine on systolic blood pressure in enalapriltreated two-kidney-one-clip rats. Caffeine was administered to half of the animals beginning $1 \mathrm{wk}$ before renal artery clipping. After obtaining baseline systolic blood pressure, all animals were subjected to renal artery clipping and $0.03 \%$ enalapril was added to their drinking water. 3 wk after surgery, the enalapril was withdrawn, and systolic blood pressure was followed for another $3 \mathrm{wk}$. Statistics in the figure refer to unpaired Student's $t$ test. After withdrawal of enalapril, the time-pressure relationships were different between the caffeine and non-caffeine-treated rats (two-way ANOVA).
Table II. Metabolic and Biochemical Studies at the End of $6 \mathrm{Wk}$ in Protocol B

\begin{tabular}{|c|c|c|}
\hline & \multicolumn{2}{|l|}{$2 \mathrm{~K}-1 \mathrm{C}$ rats } \\
\hline & Caffeine-treated & Non-caffeine-treated \\
\hline Urine volume $(\mathrm{ml} / \mathrm{d})$ & $17 \pm 1$ & $20 \pm 3$ \\
\hline Water intake $(\mathrm{ml} / \mathrm{d})$ & $32 \pm 2$ & $38 \pm 3$ \\
\hline Food intake $(g / d)$ & $20 \pm 1$ & $20 \pm 1$ \\
\hline $\begin{array}{l}\text { Plasma sodium concentration } \\
\text { (meq/liter) }\end{array}$ & $146 \pm 3$ & $147 \pm 3$ \\
\hline $\begin{array}{l}\text { Urinary sodium excretion } \\
(\mu e q / \text { liter })\end{array}$ & $1,441 \pm 179$ & $1,315 \pm 85$ \\
\hline $\begin{array}{l}\text { Plasma renin activity } \\
\quad\left(n g A I \cdot m l^{-1} \cdot h^{-1}\right)\end{array}$ & $8.1 \pm 4.2^{*}$ & $1.1 \pm 0.2$ \\
\hline Creatinine clearance $(\mathrm{ml} / \mathrm{min})$ & $2.4 \pm 0.2$ & $3.0 \pm 0.4$ \\
\hline
\end{tabular}

Values indicate mean \pm SEM.

* Indicates $P<0.05$ compared with non-caffeine-treated group ( $t$ test).

opment of hypertension in SHR. In fact, SBP tended to be lower in caffeine-treated animals compared with non-caffeine-treated animals, although this trend was not statistically significant (twoway ANOVA). Likewise, caffeine treatment did not alter water intake, food intake, plasma sodium concentration, urinary sodium excretion, plasma renin activity, or creatinine clearance in SHR (Table III). Urine volume was significantly lower in caffeine-treated SHR compared with controls, perhaps due to a greater loss of fluid in the feces; i.e., caffeine caused softer stools in SHR.

\section{Discussion}

The results of our experiments clearly indicate that caffeine exacerbates the development of renovascular hypertension in rats. The mechanism by which caffeine exacerbates renovascular hypertension most likely involves the renin-angiotensin system since caffeine increases plasma renin activity in renovascular hypertension rats, does not aggravate genetic hypertension, i.e., a normal renin model of hypertension, and the effect of caffeine

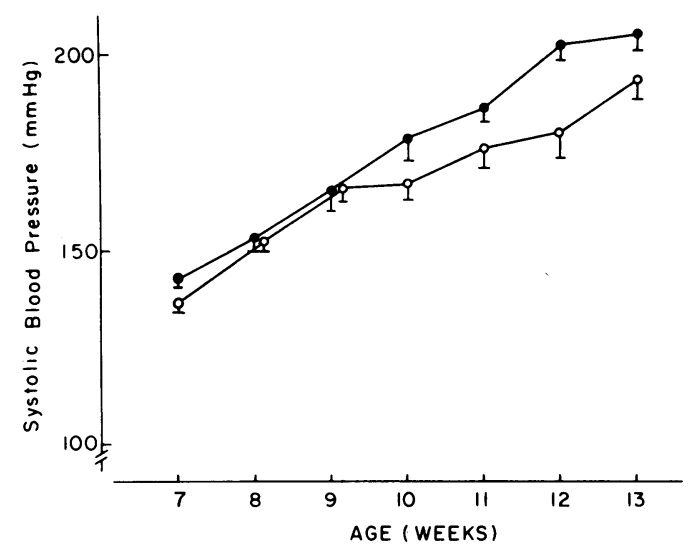

Figure 4. Effects of caffeine on systolic blood pressure in spontaneously hypertensive rats. Caffeine did not significantly alter systolic blood pressure in SHR. $\bullet$, No caffeine in drinking water $(n=8)$; $\circ$, $0.1 \%$ caffeine in drinking water $(n=8)$. 
Table III. Metabolic and Biochemical Studies at the End of $6 \mathrm{Wk}$ in Protocol C

\begin{tabular}{lcc}
\hline & \multicolumn{2}{l}{ SHR } \\
\cline { 2 - 3 } & Caffeine-treated & Non-caffeine-treated \\
\hline Urine volume $(\mathrm{ml} / \mathrm{d})$ & $13 \pm 1^{*}$ & $20 \pm 2$ \\
Water intake $(\mathrm{ml} / \mathrm{d})$ & $32 \pm 2$ & $37 \pm 2$ \\
Food intake $(\mathrm{g} / \mathrm{d})$ & $16 \pm 1$ & $18 \pm 1$ \\
$\begin{array}{l}\text { Plasma sodium concentration } \\
\quad(\text { meq/liter })\end{array}$ & $144 \pm 2$ & $146 \pm 2$ \\
$\quad \begin{array}{l}\text { Urinary sodium excretion } \\
\quad(\mu e q / \text { liter })\end{array}$ & $2,880 \pm 1,726$ & $1,538 \pm 200$ \\
$\quad \begin{array}{l}\text { Plasma renin activity } \\
\quad\left(n g \mathrm{AI} \cdot \mathrm{ml}^{-1} \cdot \mathrm{h}^{-1}\right)\end{array}$ & $1.9 \pm 0.3$ & $2.4 \pm 0.3$ \\
Creatinine clearance $(\mathrm{ml} / \mathrm{min})$ & $2.6 \pm 0.2$ & $2.6 \pm 0.2$ \\
\hline
\end{tabular}

Values indicate mean \pm SEM.

* Indicates $P<0.05$ compared with non-caffeine-treated group ( $t$ test).

on arterial blood pressure in renovascular hypertension is blocked by the angiotensin I converting enzyme inhibitor, enalapril.

Recently, we discovered that low-dose infusion of adenosine into the renal artery of dogs markedly reduces the renin release response to acute reductions in renal perfusion pressure (1). This effect of adenosine most likely is mediated via preventing the activation of renin release by prostaglandin $\mathrm{I}_{2}\left(\mathrm{PGI}_{2}\right)$, the putative extracellular mediator of renal ischemia-induced renin release (1). This interaction between adenosine and $\mathrm{PGI}_{2}$ probably is due to the specific inhibition by adenosine of hormone-induced activation of adenylate cyclase (10).

Even if the mechanism by which adenosine inhibits the renin release response to renal ischemia is more complex, the fact that this phenomenon exists suggests that endogenously produced adenosine may restrain the renin release response to renal ischemia. Adenosine normally circulates in plasma (11) and is produced in the kidney (12). Although it is not known if acute or chronic renal artery stenosis increases renal adenosine levels, adenosine production in the kidney is enhanced by severe acute renal ischemia $(13,14)$. Further, angiotensin II can stimulate adenosine release (15). Therefore, either circulating adenosine or adenosine produced in the kidney may attenuate the renin release response to chronic renal ischemia.

Production of hypertension by chronic renal ischemia is critically dependent upon activation of the renin-angiotensin system (16). Therefore, if endogenous adenosine restrains the renin response to renal ischemia, then adenosine may play an important role in attenuating the rise in arterial blood pressure in response to renal ischemia.

Caffeine is an antagonist of the adenosine receptor and is widely consumed in large doses by the world community. If adenosine does indeed restrain the renin and blood pressure response to renal ischemia, then ingestion of caffeine could exacerbate the hypertension in those patients who have renovascular hypertension. For this reason, we felt compelled to carefully examine the effects of caffeine on arterial blood pressure in an animal model of renovascular hypertension.

In renovascular hypertensive rats treated with caffeine from the onset of studies, caffeine produced a remarkable exacerbation of the hypertensive process and produced in some rats histolog- ical changes consistent with malignant hypertension. This effect of caffeine was accompanied by a sevenfold elevation in plasma renin activity, which suggests that caffeine-induced enhancement of renin release was, at least in part, responsible for the exacerbation of the hypertension. This contention is strengthened by the observations that: $(a)$ caffeine did not elevate blood pressure in animals whose kidneys were not stimulated to release large quantities of renin, i.e., sham-operated rats and spontaneously hypertensive rats, and $(b)$ caffeine did not elevate blood pressure in $2 \mathrm{~K}-1 \mathrm{C}$ animals treated with a converting enzyme inhibitor.

Although it seems clear that caffeine-induced accentuation of the renin response to renal ischemia is at least in part responsible for the effect of caffeine on arterial blood pressure, at this time we cannot be sure that this effect is mediated by blockade of adenosine receptors. Further, the renin-enhancing effect of caffeine may not be the only mechanism, or even the most important mechanism, by which caffeine exacerbates renovascular hypertension. Angiotensin II is a potent vasoconstrictor and facilitates noradrenergic neurotransmission in chronic renovascular hypertension (17). In contrast, adenosine is a vasodilator in most vascular beds and is a potent inhibitor of noradrenergic neurotransmission (18-23). Since adenosine is a physiological antagonist of angiotensin II, either circulating or locally produced adenosine may be important in reducing the effects of angiotensin II in pathophysiological states of increased angiotensin II and adenosine production. Therefore, administration of an adenosine antagonist, such as caffeine, might also elevate arterial blood pressure in renovascular hypertension by preventing adenosine from buffering the vasoconstrictive and sympathetic neurotransmission-enhancing effects of angiotensin II. In short, further studies are required to elucidate the mechanism(s) by which caffeine exacerbates renovascular hypertension.

Interestingly, caffeine consumption had less of an impact on the blood pressure of rats that had already developed hypertension compared with rats treated with caffeine from the onset of renal artery stenosis. The reason for this difference is unclear. However, one possibility is that the role of adenosine in renin release may depend on the duration of renal ischemia.

Our finding that caffeine exacerbates experimental renovascular hypertension raises a critical question: namely, to what extent, if any, does caffeine exacerbate human renovascular hypertension? Although our results in animals should not be extrapolated hastily to apply to humans, our results underscore the need to investigate the effects of caffeine in renovascular hypertensive patients. The effects of caffeine on arterial blood pressure in humans have been studied exhaustively (24-26), and it is clear that in essential hypertension caffeine is not deleterious. Thus, our data with genetic hypertension in rats are in harmony with observations in humans. However, to our knowledge, the effects of caffeine in patients with renovascular hypertension has not been examined. Since only $\sim 2 \%$ of hypertensive people have renovascular hypertension (27), and since known cases of renovascular hypertension are usually excluded from caffeine studies, it is unlikely that the effects of caffeine on arterial blood pressure in renovascular patients have been examined in a controlled study. However, given that the plasma levels of caffeine necessary to exacerbate experimental renovascular hypertension in the present study would be obtainable by a moderate to heavy caffeine user (24), it will be important to assess the significance of our findings in humans. 


\section{Acknowledgments}

This work was supported by SCOR in Hypertension Grant HL 14192, by a Grant-in-Aid from the American Heart Association with funds contributed in part by the Tennessee Affiliate, and by National Institutes of Health grant HL 35909. Dr. Jackson is an Established Investigator of the American Heart Association and Dr. Deray, Dr. Ohnishi, and Dr. Biaggioni are Merck Sharp \& Dohme International Fellows.

\section{References}

1. Deray, G., E. K. Jackson, W. A. Herzer, and R. A. Branch. 1985. Inhibition of prostaglandin mediated renin release by adenosine. Clin. Res. 33:282A. (Abstr.).

2. von Borstel, W. R., and R. J. Wurtman. 1984. Caffeine and the cardiovascular effects of physiological levels of adenosine. In Caffeine. P. B. Dews, editor. Springer-Verlag, Berlin, Federal Republic of Germany. 142-150.

3. Schwabe, U., D. Ukena, and M. J. Lohse. 1985. Xanthine derivatives as antagonists at $A_{1}$ and $A_{2}$ adenosine receptors. Naunyn Schmiedeberg's Arch. Pharmakol. 330:212-221.

4. Bunag, R. D., and J. Butterfield. 1982. Tail-cuff pressure measurement without external preheating in awake rats. Hypertension. 4: 898-903.

5. von Borstel, R. W., R. J. Wurtman, and L. A. Conlay. 1983. Chronic caffeine consumption potentiates the hypotensive action of circulating adenosine. Life Sci. 32:1151-1158.

6. Cambell, W. B., R. M. Graham, and E. K. Jackson. 1979. Role of renal prostaglandins in sympathetically mediated renin release in the rat. J. Clin. Invest. 64:448-456.

7. Workman, R. J., C. R. Sussman, and D. W. Burkitt. 1979. Circulating levels of angiotensin I measured by radioimmunoassay in hypertensive subjects. J. Lab. Clin. Med. 93:847-856.

8. Hartley, R., I. J. Smith, and J. R. Cookman. 1983. Improved highperformance liquid chromatographic method for the simultaneous determination of caffeine and its $N$-demethylated metabolites in plasma using solid-phase extration. J. Chromatogr. 342:105-117.

9. Fitzsimons, J. T. 1975. The renin-angiotensin system and drinking behavior. Prog. Brain Res. 42:215-233.

10. Deray, G., R. A. Branch, W. A. Herzer, A. Ohnishi, and E. K. Jackson. 1987. Adenosine inhibits beta-adrenoceptor, but not dibutyrylcAMP, induced renin release. Am. J. Physiol. In press.

11. Sollevi, A., M. Lagerkranser, M. Andreen, and L. Irestedt. 1984. Relationship between arterial and venous adenosine levels and vasodilation during ATP- and adenosine-infusion in dogs. Acta Physiol. Scand. 120:171-176.

12. Thompson, C. I., H. V. Sparks, and W. S. Spielman. 1985. Renal handling and production of plasma and urinary adenosine. Am. J. Physiol. 248:F545-F551.
13. Osswald, H., H.-J. Schmitz, and R. Kemper. 1977. Tissue content of adenosine, inosine and hypoxanthine in the rat kidney after ischemia and postischemic recirculation. Pfluegers Arch. Eur. J. Physiol. 371:4549.

14. Miller, W. L., R. A. Thomas, R. M. Berne, and R. Rubio. 1978. Adenosine production in the ischemic kidney. Circ. Res. 43:390-397.

15. Fredholm, B. B., and P. Hedqvist. 1978. Release of ${ }^{3} \mathrm{H}$-purines from $\left({ }^{3} \mathrm{H}\right)$-adenosine labelled rabbit kidney following sympathetic nerve stimulation and its inhibition by $\alpha$-adrenoceptor blockade. Br. J. Pharmacol. 64:239-245.

16. DeForrest, J. M., R. C. Knappenberger, M. J. Antonaccio, R. A. Ferrone, and J. S. Creekmore. 1982. Angiotensin II is a necessary component for the development of hypertension in the two kidney, one clip rat. Am. J. Cardiol. 49:1515-1517.

17. Jackson, E. K., J. B. Zimmerman, and D. H. Robertson. 1985. Angiotensin-noradrenergic interactions in renovascular hypertension. Clin. Res. 33:363A. (Abstr.)

18. Herlihy, J. T., E. L. Bockman, R. M. Berne, and R. Rubio. 1976. Adenosine relaxation of isolated vascular smooth muscle. Am. J. Physiol. 230:1239-1243.

19. Ohnishi, A., I. Biaggioni, G. Deray, R. A. Branch, and E. K. Jackson. 1986. Hemodynamic effects of adenosine in conscious hypertensive and normotensive rats. Hypertension. 8:391-398.

20. Wakade, A. R., and T. D. Wakade. 1978. Inhibition of noradrenaline release by adenosine. J. Physiol. 282:35-49.

21. Hedqvist, P., and B. B. Fredholm. 1976. Effect of adenosine on adrenergic neurotransmission; prejunctional inhibition and postjunctional enhancement. Naunyn Schmiedeberg's Arch. Pharmakol. 293:217223.

22. Fredholm, B. B., and P. Hedqvist. 1980. Modulation of neurotransmission by purine nucleotides and nucleosides. Biochem. Pharmacol. 29:1635-1643.

23. Verhaeghe, R. H., P. M. Vanhoutte, and J. T. Shepherd. 1977. Inhibition of sympathetic neurotransmission in canine blood vessels by adenosine and adenine nucleotides. Circ. Res. 40:208-215.

24. Robertson, D., J. C. Frolich, R. K. Carr, J. T. Watson, J. W. Hollifield, D. G. Shand, and J. A. Oates. 1978. Effect of caffeine on plasma renin activity, catecholamines and blood pressure. $N$. Engl. J. Med. 298:181-186.

25. Robertson, D., A. S. Hollister, D. Kincaid, R. Workman, M. R. Goldberg, C.-S. Tung, and B. Smith. 1984. Caffeine and hypertension. Am. J. Med. 77:54-60.

26. Robertson, D., D. Wade, R. Workman, R. L. Woosley, and J. A. Oates. 1981. Tolerance to the humoral and hemodynamic effects of caffeine in man. J. Clin. Invest. 67:1111-1117.

27. Kaplan, N. M. Systemic hypertension-mechanism and diagnosis. In Heart Disease, A Textbook of Cardiovascular Medicine. E. Braunwald, editor. W. B. Saunders Co., Philadelphia. 891-897. 